\title{
Carbon Dioxide-Mediated Desalination
}

Anand Sharadha-Ravi Ayyar, ${ }^{1}$ Desta Tesfay Aregawi, ${ }^{1}$ Allan R. Petersen, ${ }^{1}$ Jonas Merlin Ibsgaard Pedersen, ${ }^{1}$ Rasmus Refsgaard Kragh, ${ }^{1}$ Mohamed M. H. Desoky, ${ }^{1}$ Jonas Sundberg, ${ }^{2}$ Lars Vinum, ${ }^{3}$ Ji-Woong Lee ${ }^{1 *}$

${ }^{1}$ Department of Chemistry, Nano-Science Centre, University of Copenhagen, Universitetsparken 5, Copenhagen $\varnothing, 2100$, Denmark

${ }^{2}$ Danish Hydrocarbon Research and Technology Centre, Technical University of Denmark, Elektrovej 375, 2800 Kgs. Lyngby, Denmark

${ }^{3}$ CowaTech ApS, Torvegade 23, Copenhagen $\varnothing, 2100$, Denmark

*Correspondence to: jiwoong.lee@ chem.ku.dk

Water is arguably the most important molecule for life on Earth, providing the media in which complex chemical reactions and equilibria create the very essence of life as we know it. However, accelerated global industrialization, among other factors, is leading to unpredictability in what regards secure water supply, and is thus threatening society's sustainable growth ${ }^{1}$. Desalination of seawater or brackish water is considered to be a possible approach to secure potable water supply ${ }^{2}$. Although reverse osmosis implemented with membrane materials can lead to efficient desalination processes, more practical and low-carbon-footprint processes are required and are yet to be developed $^{3}$. We propose a potential approach of performing seawater desalination by utilizing the reversible interaction of carbon dioxide $\left(\mathrm{CO}_{2}\right)$ and nucleophilic amines. $\mathrm{CO}_{2}$-responsive amphiphilic insoluble diamines were prepared, characterized, and applied in the formation of soda and insoluble ammonium chloride upon exposure to $\mathrm{CO}_{2}$, thus removing chloride ions from modeland real seawater. A treatment with acidic resin and separation afforded desalinated water, without the need for external energy sources, accomplishing conceptual desalination by only using catalytic resources: $\mathrm{CO}_{2}$ and recyclable diamines which can be regenerated via acid-base chemistry.

A solution of seawater consists mainly of sodium chloride ( $85.6 \%$ of solubilized ions by weight), which exhibits a positive enthalpy of solution $(3.88 \mathrm{~kJ} / \mathrm{mol})$. However, the high solvation energy of ions in water hinders the liquid-liquid and solid-liquid extraction of salt — namely sodium and chloride ions-from water ${ }^{4}$. To circumvent the use of heat and electrical energy in a desalination process, we envisaged that a recognition of sodium and chloride ions will be critical for the success of desalination. Chlorides in aqueous systems pose a significant environmental and agricultural threat, because of the excessive use of water softener that their presence implies ${ }^{5,6}$. Various chloride ion recognition and sequestration processes in aqueous solutions have been reported, mainly in the realm of supramolecular host-guest chemistry with sophisticated receptors, which require strenuous synthetic procedures ${ }^{7-12}$. Recently, polymeric variants of host-guest chemistry showed a promising performance in chloride ion capture, an approach that may lead to a whole new path for desalination processes ${ }^{13-15}$. 
Carbon dioxide is one of the most problematic greenhouse gases, however, its low toxicity and accessibility prompted us to apply it in water purification and desalination processes. Sequestration of heavy metal ions from aqueous media has been achieved by harnessing the reactivity of amines with $\mathrm{CO}_{2}$, with insoluble oligomeric amines providing heterogeneous environments to form separatable complexes ${ }^{16-18}$. Another such example is the Solvay process (Fig 1, Left) - a process for industrial production of soda ash from seawater, $\mathrm{CO}_{2}$, and ammoniaoperates based on $\mathrm{CO}_{2}$-amine chemistry, by providing an ion exchange system that precipitates out sodium bicarbonate from the basic solution ${ }^{19}$. In the process, the water-soluble ammonium chloride is treated with a base, namely $\mathrm{CaO}$, to regenerate the "catalytic" amine and $\mathrm{CO}_{2}$.

Various organic amines can reversibly form complexes with carbon dioxide, resulting in the thermally labile carbamate and bicarbonate/carbonate salts ${ }^{20,21}$. Under reduced pressure or mild heat, dissociation of $\mathrm{CO}_{2}$ from the diamines occurs, and the parent diamines can be regenerated. This reversible carbon dioxide capture process has been applied in carbon capture processes ${ }^{22}$, switchable solvents ${ }^{16}$, and heavy metal extraction ${ }^{17,23} \cdot \mathrm{CO}_{2}$-responsive autonomous aggregation (or precipitation) was controlled by polarity alteration of the monomeric entity, which is key to induce this dynamic behaviour ${ }^{24}$. An example of the spontaneous self-assembly of nanomaterials was demonstrated by decorating gold nanoparticles with diamines, upon which the materials selfaggregate, driven by the surface polarity changes of nanoparticle on $\mathrm{CO}_{2}$ exposure ${ }^{25}$.

Given the above discussed precedents, and as a working hypothesis, we envisioned that reversible $\mathrm{CO}_{2}$-responsive formation of ammonium bicarbonate could induce spontaneous ion exchange with anions from a feeding solution ${ }^{26}$. The sodium ions could then be removed from seawater via the formation of bicarbonate using the so-called dual alkali approach, which mimics the Solvay process ${ }^{27,28}$. However, to achieve complete desalination, it would still be necessary to remove water soluble ammonium chloride $\left(\mathrm{NH}_{4} \mathrm{Cl}\right)$. We hypothesized that this process could be controlled by insoluble diamines or polymeric $\mathrm{CO}_{2}$-responsive materials, thus controlling the
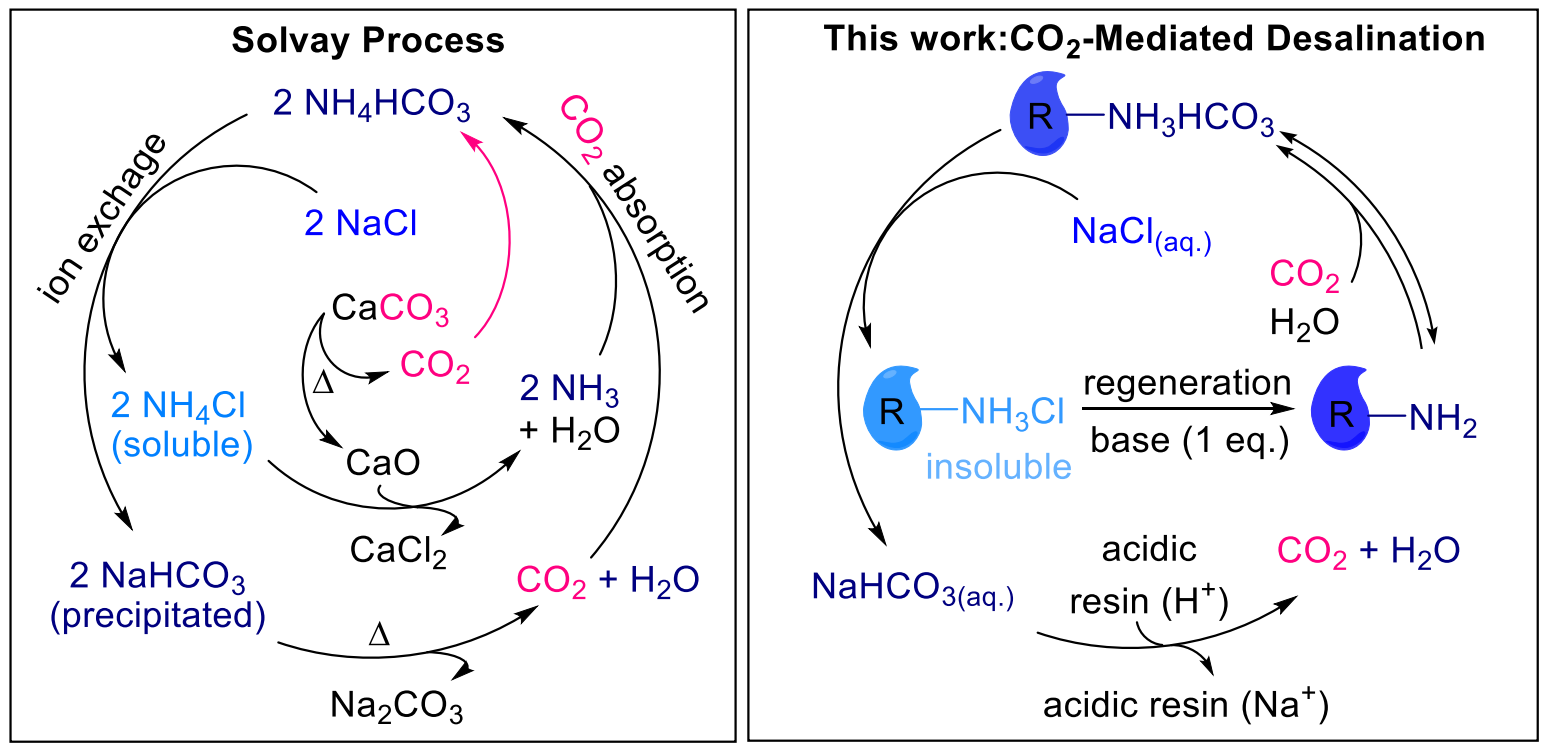

Fig 1. Schematic representation of Solvay process (left) and desalination (right) mediated by $\mathrm{CO}_{2}$ and insoluble diamines $\left(\mathrm{R}-\mathrm{NH}_{2}\right)$, respectively. 
solubility of ammonium chloride salt, $\mathrm{RNH}_{3} \mathrm{Cl}^{27,28}$. The insoluble alkyl ammonium chloride could then be collected, regenerated, and recycled via mild heating or base treatment, considering the reversibility of $\mathrm{CO}_{2}$-diamine interactions and the low decomposition temperatures of bicarbonate salts (i.e., thermal decomposition of $\mathrm{NaHCO}_{3}$ and $\mathrm{NH}_{4} \mathrm{HCO}_{3}: 80$ and $36-58^{\circ} \mathrm{C}$, respectively), thus providing a more energy-efficient catalytic desalination than the traditional thermal and reverse osmosis processes.

\section{Results and Discussion}

To accelerate the screening of the functional groups of $\mathrm{CO}_{2}$-responsive organic materials to be used in the proposed desalination application, we evaluated the performance of diamines in terms of conductivity, a measure that can provide information on the mobilities of ions, viscosity, and $\mathrm{CO}_{2}$ responsiveness. We performed the screening experiments using a model seawater solution (20 mL, NaCl $35 \mathrm{~g} / \mathrm{L}$ ) with an organic compound (10 wt\%, approximately 10 equivalents based on $\mathrm{NaCl}$ ) and $\mathrm{CO}_{2}(99.6 \%$ purity, $>50 \mathrm{~mL} / \mathrm{min})$. We extensively tested several nitrogen-based compounds. As summarized in Figure S1, most of the conventional diamines, amino alcohols and their derivatives resulted in a homogeneous solution and, therefore, mostly increased the

(A)

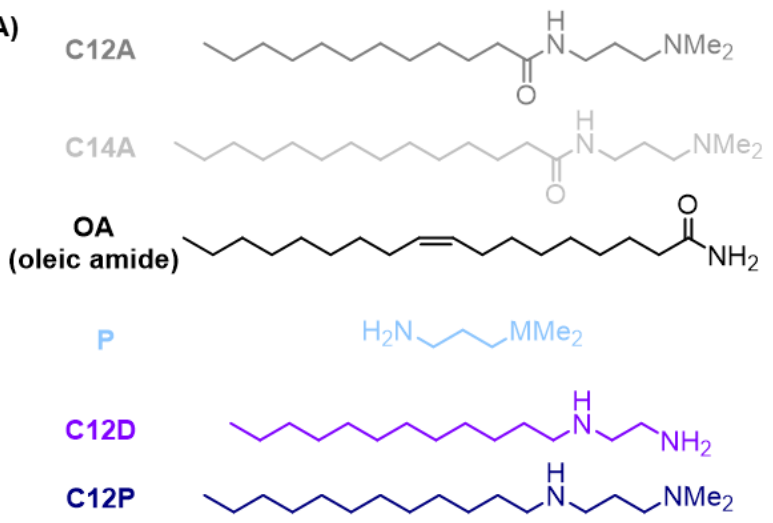

(B)

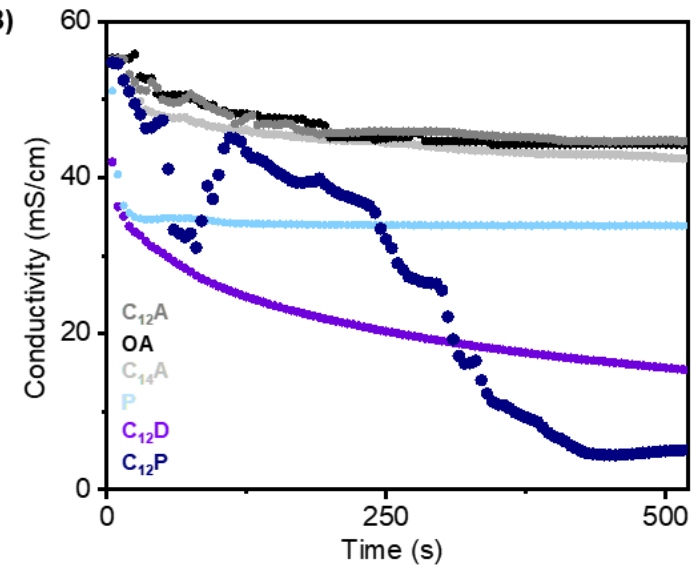

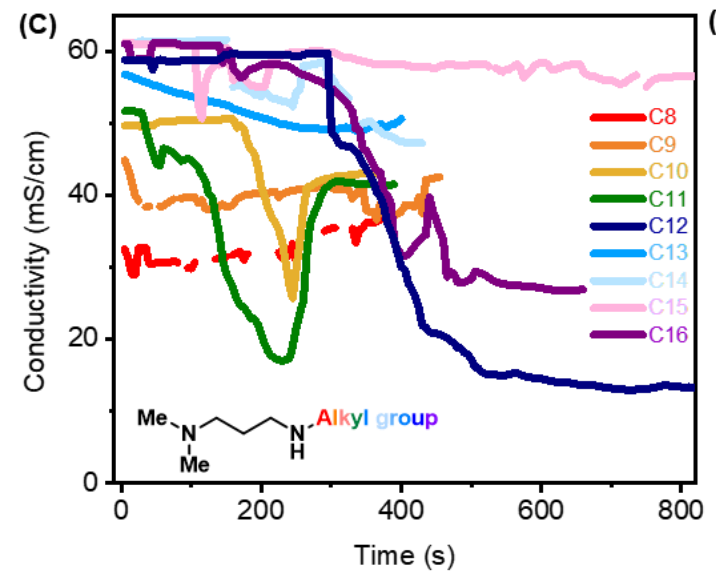
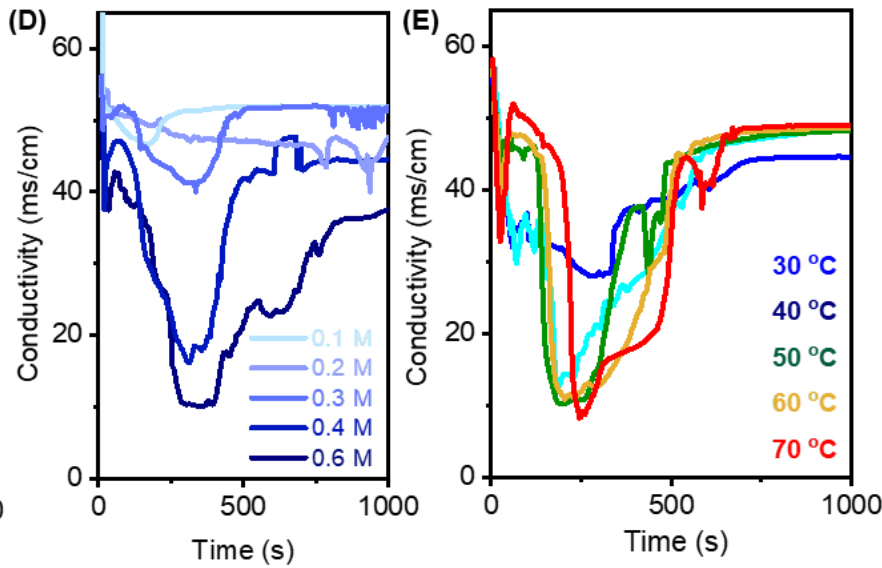

Fig 2. (A) Chemical structures of representative amines. Conductivity measurements with continuous $\mathrm{CO}_{2}$ injection $(99.9 \%, 15 \mathrm{~mL} / \mathrm{min}$, open system) into diamine-containing saline solutions at room temperature. Effects of (B) different $\mathrm{CO}_{2}$-responsive molecules, (C) chainlength of the diamine, (D) different concentration of the diamine, and (E) different temperatures. 
conductivity of the solution (up to $90 \%$ ). This can be ascribed to the increased concentration of ammonium carbonate and bicarbonate ions in the solution, without phase separation. Alkylated diamines (Fig 2A), however, showed a dramatic conductivity reduction, as a result of spontaneous and reversible hydrogel formation. Further optimizations revealed that both tertiary and secondary amines are critical. $N, N^{\prime}$-dimethyl-1,3-propanediamine $(\mathbf{P})$ showed the highest observed reduction of conductivity (92\% within 2-10 minutes) when alkylated with a $\mathrm{C}_{12}$ unit (C12P, Fig 2B). We evaluated some critical molecular functional groups - long alkyl chain (>C10) and diamine groups with a secondary and a tertiary amine. Next, we quickly verified that the chain length of the alkylated diamines plays a significant role in the $\mathrm{CO}_{2}$-absorption and conductivity reduction and, therefore, should heavily affect the performance (Fig 2C). It became clear that the chain length C11-C12 is optimal, with longer chain lengths (C13-C16) being detrimental because of their insolubility in water, both with and without $\mathrm{CO}_{2}$. The optimal diamine $(\mathbf{C 1 2 P})$ showed critical micelle formation concentration (CMC) at around $0.3 \mathrm{M}$ at room temperature (Fig 2D). The presence of $\mathrm{CMC}$ indicates the importance of the self-aggregation feature, which is sensitive toward $\mathrm{pH}$ : disaggregation was observed after continuously injecting $\mathrm{CO}_{2}$. An acidic medium was formed after 10 minutes of continuous $\mathrm{CO}_{2}$ bubbling, reaching $\mathrm{pH}$, when the formation of micelles was reversed based on the measurement of viscosity and DLS (dynamic light scattering, Figures S8 and S9). A higher conductivity reduction was obtained at higher temperatures, even though a full recovery of the conductivity was detected after 10 minutes (Fig 2E). We postulated that the hydrophobicity of $\mathbf{C 1 2 P}$ was increased at higher temperatures, leading to a more significant conductivity reduction, induced by the formation of micelles with random size distribution ${ }^{29}$. Further investigations in larger-scale experiments (1L of model seawater with C12P) were conducted under a continuous measurement of $\mathrm{pH}$ and conductivity (Fig S6). We confirmed that the turbidity and solubility of the diamines were directly correlated with the observed $\mathrm{pH}$, which can be controlled by the amount of $\mathrm{CO}_{2}$ injected to form carbonic acid, bicarbonate, and carbonate ions. By measuring the gas feed at inlet and outlet, we determined that approximately 0.33 equivalents of $\mathrm{CO}_{2}$ were needed to reach minimum conductivity (Fig S7), presumably by forming mostly ammonium bicarbonate salts. During the process, the $\mathrm{pH}$ of the solution was increased to 10.5 after the addition of C12P, but afterwards dropped dramatically, buffering at $8-9\left(p \mathrm{~K}_{\mathrm{a}}\right.$ of alkylammonium chloride $=$ ca. $9-10$, carbonic acid $\left.=6\right)$, the point where the lowest conductivity was observed. It is important to note that the measured conductivity is not correlated with the salinity of the solution, given that the mixture of diamine and $\mathrm{CO}_{2}$ in $\mathrm{NaCl}$ solutions forms a turbid mixture with unidentifiable aggregates. DLS measurements suggest the formation of aggregated particles (ca. $700 \mathrm{~nm}$ ), albeit with a random and broad distribution of particle sizes (Fig S9). A mathematical analysis based on the theoretical molar conductivity of $\mathrm{Na}^{+}, \mathrm{Cl}^{-}, \mathrm{HCO}_{3}{ }^{-}, \mathrm{H}^{+}$, and hydroxide confirmed a $23 \%$ conductivity reduction when a quantitative anion exchange occurs with 0.33 equivalents of bicarbonate from $\mathrm{CO}_{2}$. Therefore, the extra reduction of conductivity in our experiments can be attributed to the formation of aggregates, which affects the mobility of ions in the solution.

To verify the applicability of our method to the removal of chloride from sea water, we used broad range ${ }^{23} \mathrm{Na}$ and ${ }^{35 / 37} \mathrm{Cl}$ NMR spectroscopy to determine the concentrations of sodium and chloride ions in the solution before and after the $\mathrm{CO}_{2}$-diamine process (Table 1). The solution with a treatment of only diamine or only $\mathrm{CO}_{2}$ showed no significant differences from the nontreated water sample (entries 1 and 2). We observed a reduction of chloride ions of up to 27\% after membrane (cut off range $10 \mathrm{~K} \mathrm{Da}$ ) and filter paper filtration (entries 3 and 4). This experiment manifested the formation of insoluble particles containing chloride ions, with the sodium ions still 
being retained in the solution by forming bicarbonate counter anions. An argentometry (Mohr method) and high-pressure ion chromatography (HPIC) analysis further confirmed the sequestration of chloride ion from the aqueous phase, while the analysis of organic and inorganic carbon showed a quantitative yield of bicarbonate ions that is in accordance (in terms of mass balance) with the anion exchange process.

Table 1. Salinity reduction measured by conductivity, silver titration, benchtop ${ }^{23} \mathrm{Na},{ }^{35 / 37} \mathrm{Cl}$ NMR, and HPIC.

\begin{tabular}{|c|c|c|c|c|c|c|c|c|}
\hline \multirow[t]{2}{*}{ Entry } & \multirow[t]{2}{*}{ Sample } & \multirow[t]{2}{*}{$\begin{array}{l}\mathrm{PSU} \\
(\mathrm{g} / \mathrm{L}) *\end{array}$} & \multirow{2}{*}{$\begin{array}{c}\mathrm{AgCl} \\
\text { titration } \\
\mathrm{NaCl}^{-} \mathbf{C l}^{-} \\
(\mathrm{g} / \mathrm{L})\end{array}$} & \multicolumn{2}{|c|}{$\begin{array}{l}\text { Low-field } \\
\text { NMR }\end{array}$} & \multicolumn{2}{|c|}{ HPIC } & \multirow[t]{2}{*}{ Remark } \\
\hline & & & & $\begin{array}{l}{ }^{23} \mathrm{Na} \\
(\mathrm{g} / \mathrm{L})\end{array}$ & $\begin{array}{l}{ }^{35} \mathrm{Cl} \\
(\mathrm{g} / \mathrm{L})\end{array}$ & $\begin{array}{l}\mathrm{Na}^{+} \\
(\mathrm{g} / \mathrm{L})\end{array}$ & $\begin{array}{c}\mathrm{Cl}^{-} \\
(\mathrm{g} / \mathrm{L})\end{array}$ & \\
\hline 1 & $35 \mathrm{~g} / \mathrm{L} \mathrm{NaCl}$ & 36,0 & $35.00 / 21.25$ & 15,5 & 21,4 & 13,4 & 20,5 & untreated \\
\hline 2 & $\mathrm{C12} / \mathrm{no} \mathrm{CO}_{2}$ & 34,1 & 35.7 & 14,7 & 21,2 & 13,4 & 20,4 & - \\
\hline 3 & $\mathrm{C12} / \mathrm{CO}_{2}$ & 3.2 & 22.6 & 15.88 & 15,74 & 9,6 & 14,9 & $\begin{array}{c}10 \mathrm{~K}- \\
\text { cutoff UF }\end{array}$ \\
\hline 4 & $\mathrm{C} 17 \mathrm{~A} / \mathrm{CO}_{2}$ & 26 & $33.33 / \mathbf{2 0 . 2 3}$ & 14.54 & 18.58 & 13.12 & 18.63 & $\begin{array}{l}\text { filter } \\
\text { paper }\end{array}$ \\
\hline 5 & PEIC16/CO ${ }_{2}$ & 26,2 & $31.03 / \mathbf{1 8 . 8 4}$ & 11,66 & 15,86 & 11.01 & 16.38 & $\begin{array}{l}\text { filter } \\
\text { paper }\end{array}$ \\
\hline
\end{tabular}

*Measured by a conductivity meter. UF: membrane ultra-filtration. Pore size of filter paper: 8

$$
12 \mu \mathrm{m} \text {. }
$$

We then addressed the difficulties associated with the separation and regeneration of small organic compounds by preparing polymeric and resin-bound materials, an approach that should enable a more efficient recovery of the diamine and minimize the risk of potential contamination of the purified water with excess solubilized diamines. Polyethyleneimines (PEI) - amine-based polymers $^{30}$ - were initially chosen to optimize the functional groups by their varying branching degrees, hydrophobicity and molecular weight, parameters that can control the compatibility of polymers in water $^{31}$. The chemical functionalization of commercially available PEI was straightforward, and alkyl chain-modified PEIs with different alkyl chain lengths (C8-C16) were generated (Fig 3A). We also varied the stoichiometry of the alkyl halide reagents to control the amphiphilicity of the modified PEIs. Among these, for example, C16-alkylchain modified PEI (with an average molecular weight of $750,000 \mathrm{~g} \cdot \mathrm{mol}^{-1}$ ), upon exposure to $\mathrm{CO}_{2}$ in saline water (35 $\mathrm{g} / \mathrm{L} \mathrm{NaCl}$ ), presented a higher ion-exchange capacity than others. We observed up to $7 \mathrm{~g} / \mathrm{L}$ of chloride ion captured in the polymer, providing $>99 \%$ of recovered water $(0.99 \mathrm{~L}$, Table 1 , entry 5 ) after simply filtering the mixture with conventional filter paper. We then evaluated the effect of the alkylation degree (20-50\%, when compared to nitrogen atoms; Fig 3B). PEI-750K-20\% at a lower alkylation degree afforded a gel-state morphology, while a higher than $30 \%$ alkylation resulted in a powder form. Although a higher reduction of conductivity was obtained with PEI750K-20\%, we evaluated our process with PEI-750K-30\%, for convenience. The quantity of 
PEI-750K-30\% was important to maintain an equimolar ratio below one-compared with the $\mathrm{NaCl}$ from the mixing. We found that a 0.9 equimolar ratio of the polymer showed the highest chloride removal performance: $>50 \%$ of chloride ions were removed after five cycles periods,
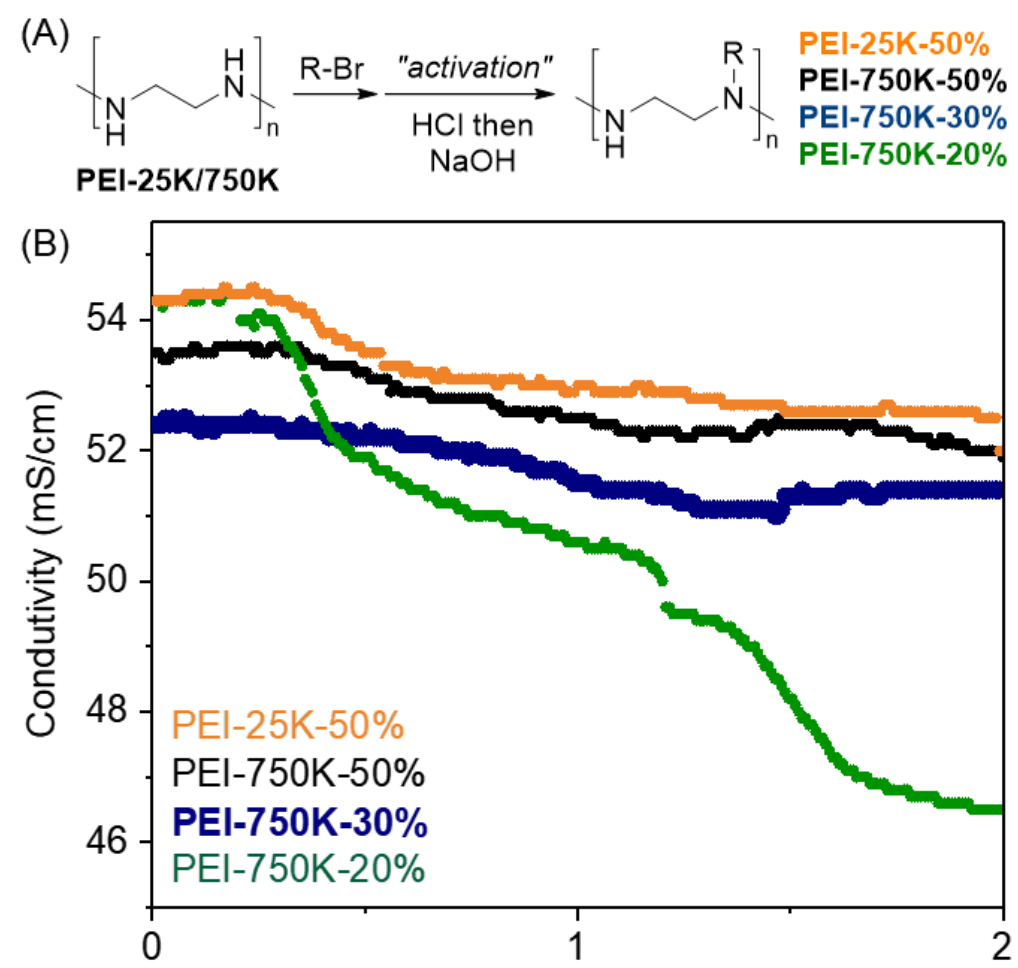

(C)

Time (hr)

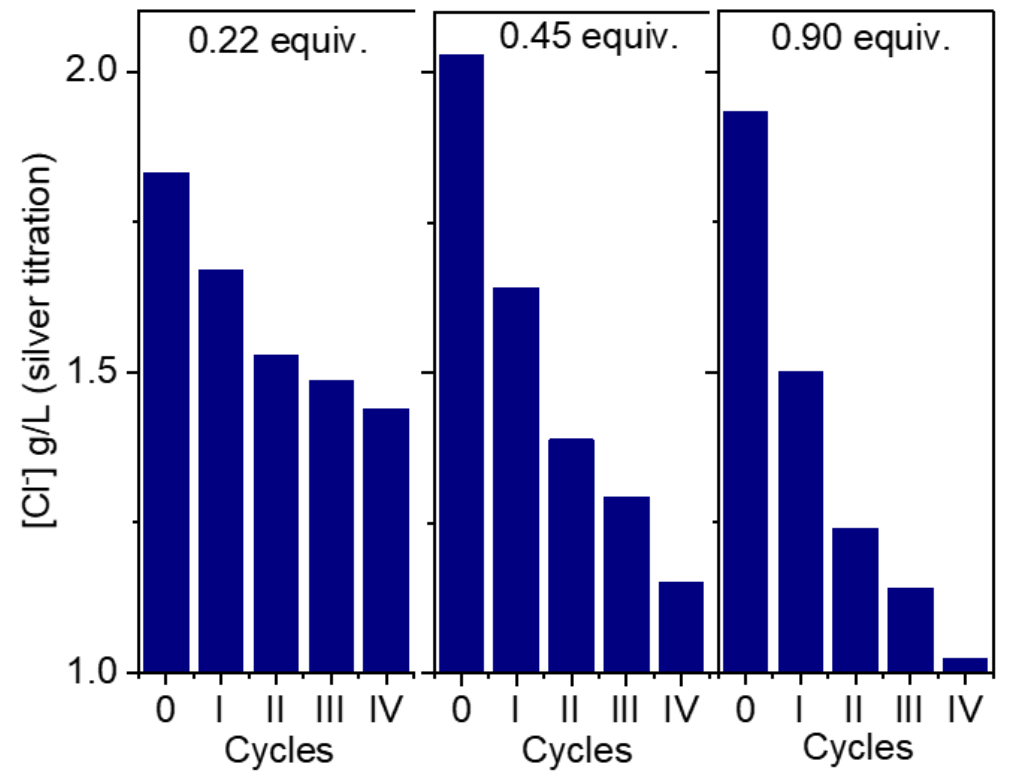

Fig 3. (A) Modification of PEI and (B) desalination using PEI-based polymers with $35 \mathrm{~g} / \mathrm{L}$ $\mathrm{NaCl}$ solution. Continuous desalination of saline water filtrate using PEI-750K-30\% . (C) Effect of molar ratio between PEI-polymers and $\mathrm{NaCl}$ for $3 \mathrm{~g} / \mathrm{L} \mathrm{NaCl}$ model seawater solution. 


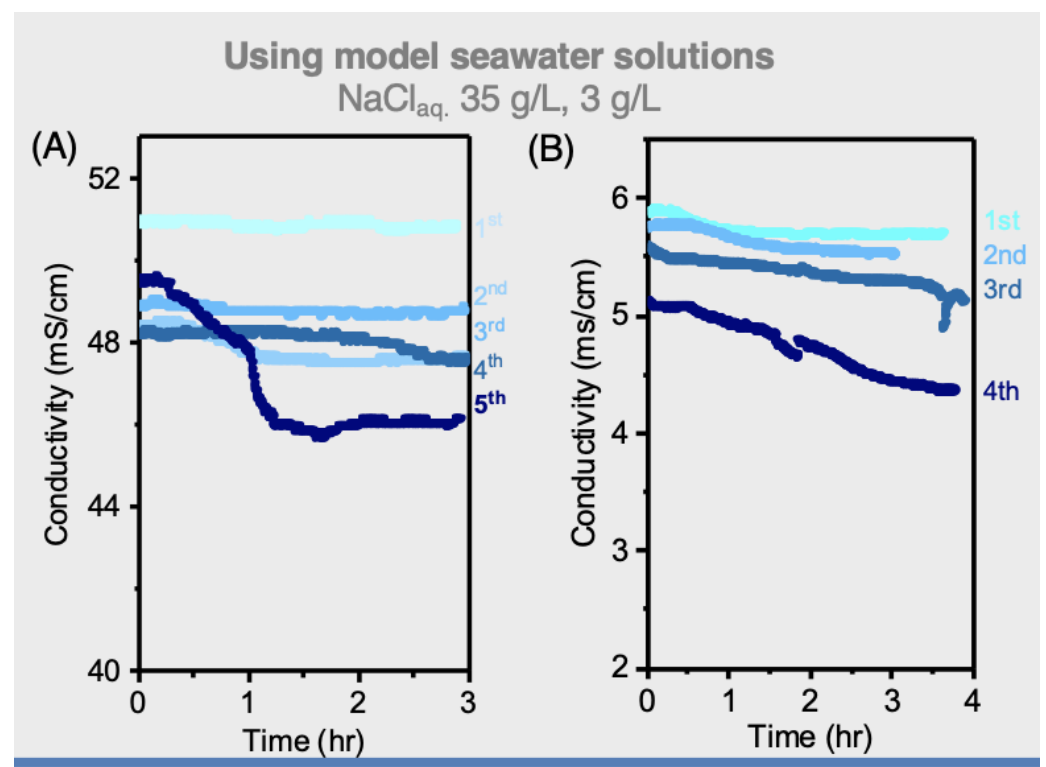

Using real seawater solutions

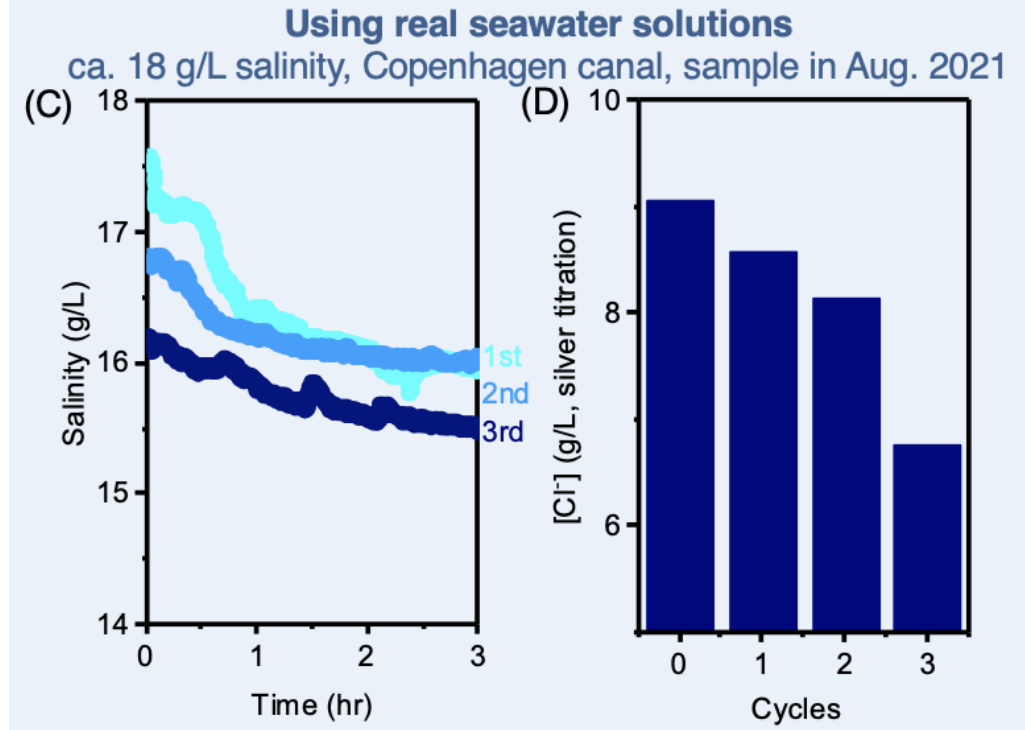

Fig 4. Repeated chloride removal using freshly prepared PEI-750K-30\% starting from (A) model seawater and (35 g/L and (B) $3 \mathrm{~g} / \mathrm{L} \mathrm{NaCl}$ model seawater solutions, (C) salinity and (D) chloride ion concentration measurements of real seawater chloride removal after a cycle of $\mathrm{CO}_{2}$ bubbling experiments.

based on NMR analysis, silver titration, conductivity measurement, and HPIC analysis, starting from a $3 \mathrm{~g} / \mathrm{L} \mathrm{NaCl}$ model seawater solution (Fig 3C). It is noteworthy that the solution became basic after the fifth cycle, due to the significant in-situ generation of $\mathrm{NaHCO}_{3}$, and, therefore, the conductivity measurement was not reliable as a proxy to analyse chloride concentration.

When we started the experiments with a higher concentration $(0.6 \mathrm{M} \mathrm{NaCl}=35 \mathrm{~g} / \mathrm{L} \mathrm{NaCl})$, the conductivity and chloride concentration showed a reduction of up to $15 \%$ after the fifth cycle. (Fig 4A). A higher degree of chloride ion exchange was obtained from lower salinity water samples $(0.045 \mathrm{M}, 3 \mathrm{~g} / \mathrm{L} \mathrm{NaCl}$, Fig 4B). A preliminary test with real seawater samples (obtained from the Copenhagen canal in August 2021) showed a consistent $\mathrm{CO}_{2}$ effect on chloride ion removal, manifesting the robust ion-exchange mechanism in the presence of an ammonium 
bicarbonate/carbonate system. A silver titration and HPIC analysis of the remaining seawater confirmed the efficient chloride ion removal, over $20 \%$ of chloride ions by simply bubbling the solution of seawater with $\mathrm{CO}_{2}$ in the presence of the polymer (Figs 4C and 4D).

The polymer was easily recyclable after washing it with a $\mathrm{KOH}$ solution (marked with stars, after $5^{\text {th }}$ cycle) affording quantitative recovery yields of the polymers. The polymers then was used for further cycles, exhibiting compatible ion exchange capacity under $\mathrm{CO}_{2}$ conditions for up to 10 cycles (Fig 5A). The chemical and physical stability of the optimal polymer PEI-750K30\% was investigated by ${ }^{1} \mathrm{H}$ NMR spectroscopy and TGA analysis, thus confirming the regeneration of the free amines under our regeneration conditions (Figs S12-19). In addition, the

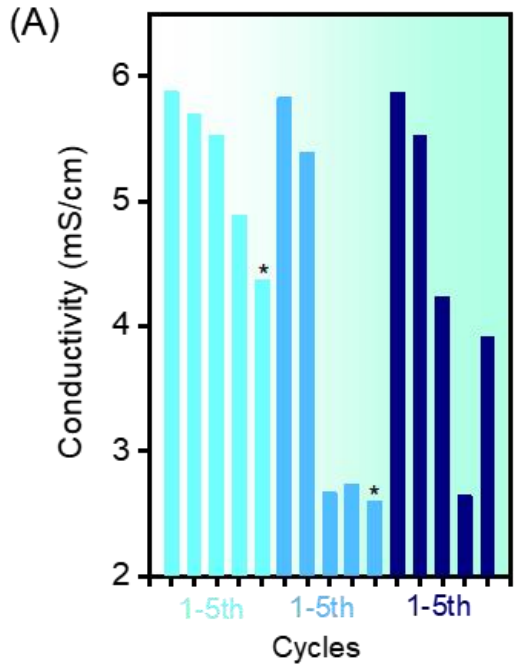

(B) Diamine-modified resin

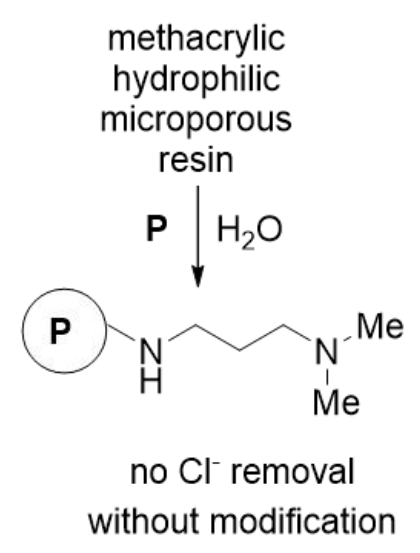

(D)

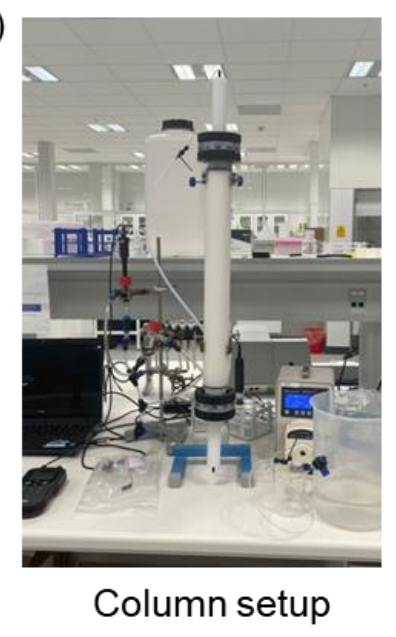

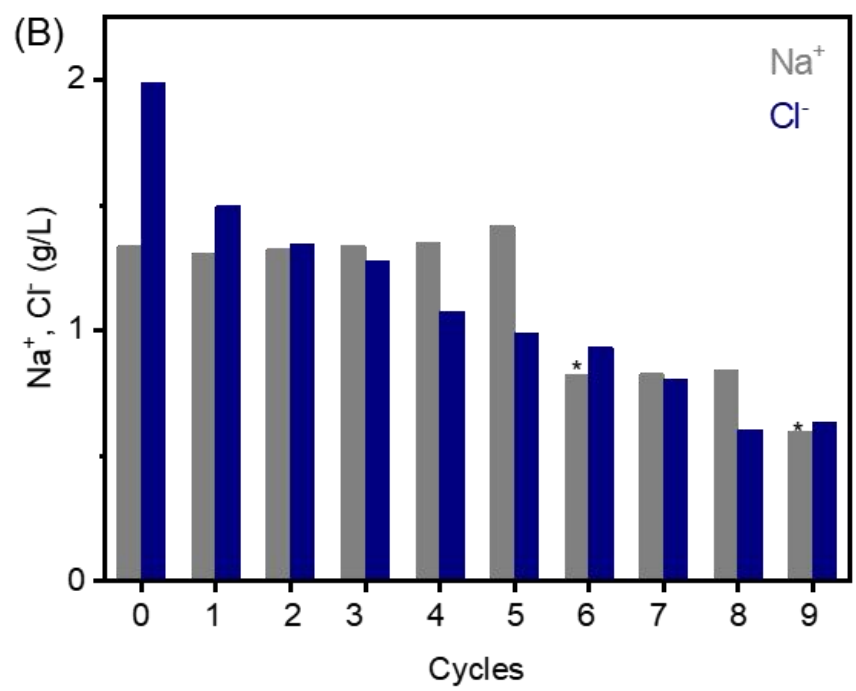

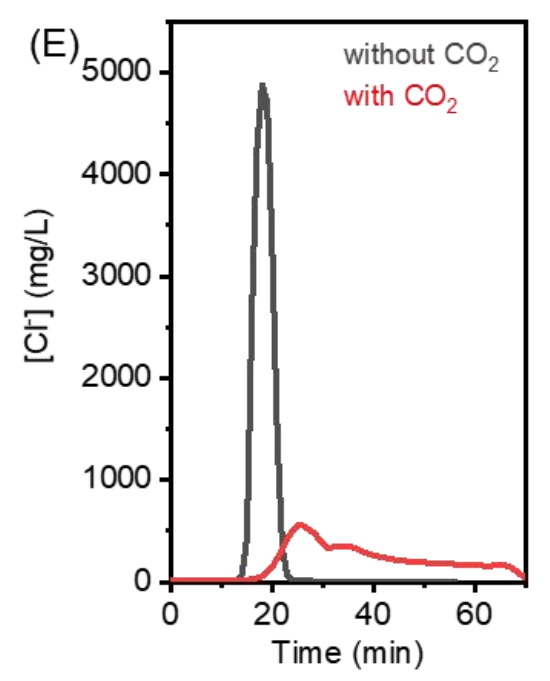

Fig 5. Repeated chloride removal using (A) regenerated PEI-750K-30\% as marked as *starting from model seawater solution $(3 \mathrm{~g} / \mathrm{L}) * A$ After $5^{\text {th }}$ cycle, the polymer was regenerated using $\mathrm{KOH}$ (B) sodium ion removal by sulfonic acid-based resin (indicated by $*$ at $6^{\text {th }}$ and $9^{\text {th }}$ cycle). (C) A scheme for preparation of diamine-modified resin, (D) column setup for breakthrough experiments, (E) Breakthrough experiments with diamine-modified resin without and with $\mathrm{CO}_{2}$. 
analysis of the filtrate water showed no detectable diamine or PEI units, indicating that the PEIs were stable under both the $\mathrm{CO}_{2}$ conditions and the regeneration process. The in-situ generated $\mathrm{NaHCO}_{3}$ was conveniently removed by treating the filtrate solution with a commercially available sulfonic acid-based resin $\left(6^{\text {th }}\right.$ and $9^{\text {th }}$ cycles, Fig 5B), decomposing $\mathrm{NaHCO}_{3}$ to $\mathrm{CO}_{2}$ and water while sequestrating sodium ion as sulphate on the polymer. This process overall completes the removal of sodium and chloride ions without external energy input. Considering that $\mathrm{CO}_{2}$ had been utilized as a regenerant for cation exchange resins, we believe that the $\mathrm{CO} 2$ can be a sole input in complete desalination, at least, from low salinity brine solutions ${ }^{32,33}$. To provide conceptual feasibility of our desalination solution, we synthesized a diamine-modified resin (Fig 5C) for continuous ion-exchange process in a one-litre column (Fig 5D). We performed a set of breakthrough experiments showing a high chloride ion removal rate (up to $90 \%$ from $0.08 \mathrm{M}$ $[\mathrm{NaCl}], 20 \mathrm{~mL} / \mathrm{min}$ ) after purging the amine-packed column with pure $\mathrm{CO}_{2}$ (Fig 5E). The captured chloride ions were quantitatively recovered after treating the column with a basic $\mathrm{KOH}$ solution (See Supplementary Text) in turn providing regenerated resin materials. It is important to note here that the regenerated resin can be reused for next cycles of chloride removal without noticeable performance changes. No ion-exchange activity was observed without $\mathrm{CO}_{2}$, implying that ionexchange process only occurs after in-situ formation of ammonium bicarbonate. A resin without the diamine modification also showed no activity toward $\mathrm{CO}_{2}$ in chloride ion removal (See Supplementary Text). Compared to traditional ion exchange resin, the ammonium chloride of PEIC16 can be regenerated with stoichiometric amounts of a base, while excess amounts of hydroxide ion are prerequisite for the regeneration of quaternary ammonium-based resins ${ }^{34}$. Furthermore, our process provides mildly basic bicarbonate solution at the efflux, thus potentially applicable for controlling chloride concentrations in providing soft water and desalinating low concentration brine feed where RO membranes exhibit a lower performance. A dual-alkali process can be applied to precipitate and remove sodium carbonate/bicarbonate, thus completing the desalination with modified resin, polymers, and monomers. The cost and energy input, with current setups, is associated with resin regeneration which requires $\mathrm{NaOH}$ for ammonium chloride salt of PEI and $\mathrm{HCl}$ for sodium salt of sulfonate resin. Without sophisticated modelling, the energy consumption for the production of $\mathrm{HCl}$ and $\mathrm{NaOH}$ based on Chloralkali process (brine electrolysis) can be translated for the regeneration cost: approximately $3.9 \mathrm{kwh} / \mathrm{t}$ desalination at $3 \mathrm{~g} / \mathrm{L}$ salinity based on the energy efficiency of Chloralkali process $\left(2500 \mathrm{kwh} / \mathrm{t}\right.$ produced $\left.\mathrm{Cl}_{2}\right)$ in $2004 .{ }^{35}$ Normal RO desalination requires thus our $\mathrm{CO}_{2}$-mediated desalination can be competitive to $\mathrm{RO}$ desalination systems (3-10 kwh/t of desalinated water) when the $\mathrm{CO}_{2}$-mediated process is further optimized. Therefore, further investigation in desalination in continuous flow reactors is underway.

Acknowledgments: The generous support of the Department of Chemistry, University of Copenhagen, Ministry of Environment, Denmark (MUDP) and the Villum Fonden (00019062) is gratefully acknowledged. The authors appreciate G. Holm, M. M. Klausen, C. Thiersant for experimental contributions and proofreading. We appreciate our friends who graciously brought us real seawater samples from all over the world. CowaTech ApS appreciates the generous support from Aquaporin for providing laboratory facilities.

Author contributions: J.W.L. formulated the project and wrote the paper, and all authors contributed to the paper's revision. R.R.K., A.R.P., M.M.H.D., D.T.A., and L.V. synthesized and characterized diamines and collected conductivity data. L.V. conducted breakthrough experiments at CowaTech ApS. J.M.I.P synthesized and evaluated amides. J. S. conducted HPIC analysis. A.A. conducted polymer synthesis and evaluation. 
Competing interests: The authors declare the existence of a financial/non-financial competing interest.

Data and materials availability: All data is available in the main text or the supplementary information.

\section{Supplementary Information:}

Materials and Methods

Supplementary Text

Figures S1-S22

\section{References and Notes}

1. UN sustainable development goals, goal 6 clean water and sanitation, https://www.un.org/sustainabledevelopment/water-and-sanitation/

2. R. F. Service, Desalination Freshens Up. Science 313, 1088 (2006).

3. M. Elimelech, W. A. Phillip, The Future of Seawater Desalination: Energy, Technology, and the Environment. Science 333, 712 (2011).

4. S. Kubik, Anion recognition in water. Chem. Soc. Rev. 39, 3648-3663 (2010).

5. M. A. Shannon et al., Science and technology for water purification in the coming decades. Nature 452, 301-310 (2008).

6. Q. Lu, H. Shim, Comparison of chloride effect between A2O and SBR processes treating domestic wastewater. Desalin. Water Treat. 53, 2549-2554 (2015).

7. Q. He et al., Selective Solid-Liquid and Liquid-Liquid Extraction of Lithium Chloride Using Strapped Calix[4]pyrroles. Angew. Chem. Int. Ed. 57, 11924-11928 (2018).

8. K. P. McDonald et al., Quantifying chloride binding and salt extraction with poly(methyl methacrylate) copolymers bearing aryl-triazoles as anion receptor side chains. Chem. Commun. 50, 13285-13288 (2014).

9. D. Jagleniec, S. Siennicka, Ł. Dobrzycki, M. Karbarz, J. Romański, Recognition and Extraction of Sodium Chloride by a Squaramide-Based Ion Pair Receptor. Inorg. Chem. 57, 12941-12952 (2018).

10. Y. Chen et al., Selective Recognition of Chloride Anion in Water. Org. Lett. 22, 48784882 (2020).

11. Y. Liu, W. Zhao, C.-H. Chen, A. H. Flood, Chloride capture using a C-H hydrogenbonding cage. Science 365, 159 (2019).

12. B. A. Moyer, P. V. Bonnesen, R. Custelcean, L. H. Delmau, B. P. Hay, Strategies for using host-guest chemistry in the extractive separations of ionic guests. Kem. Ind 54, 6587 (2005).

13. H. Wang, X. Ji, M. Ahmed, F. Huang, J. L. Sessler, Hydrogels for anion removal from water. J. Mater. Chem. A 7, 1394-1403 (2019).

14. Y. Hoshino et al., Combining Acid- and Base-Imprinted Nanoparticles in a Hydrogel Film for Temperature-Responsive Quick and Reversible Capture of Salt. ACS Appl. Poylm. Mater. 2, 505-514 (2020).

15. X. Ji et al., Removal of Anions from Aqueous Media by Means of a Thermoresponsive Calix[4]pyrrole Amphiphilic Polymer. Chem. Eur. J. 24, 15791-15795 (2018).

16. Y. Liu, P. G. Jessop, M. Cunningham, C. A. Eckert, C. L. Liotta, Switchable Surfactants. Science 313, 958 (2006). 
17. J. Septavaux et al., Simultaneous $\mathrm{CO}_{2}$ capture and metal purification from waste streams using triple-level dynamic combinatorial chemistry. Nat. Chem. 12, 202-212 (2020).

18. G. Poisson, G. Germain, J. Septavaux, J. Leclaire, Straightforward and selective metal capture through $\mathrm{CO}_{2}$-induced self-assembly. Green Chem. 18, 6436-6444 (2016).

19. D. M. Kiefer, Soda ash, Solvay style. Today's Chemist at Work 11, 87-88, 90 (2002).

20. N. McCann et al., Kinetics and Mechanism of Carbamate Formation from $\mathrm{CO}_{2}(\mathrm{aq})$, Carbonate Species, and Monoethanolamine in Aqueous Solution. J. Phys. Chem. 113, 5022-5029 (2009).

21. M. Caplow, Kinetics of carbamate formation and breakdown. J. Am. Chem. Soc. 90, 6795-6803 (1968).

22. G. Astarita, Carbon dioxide absorption in aqueous monoethanolamine solutions. Chem. Eng. Sci. 16, 202-207 (1961).

23. J. Septavaux, G. Germain, J. Leclaire, Dynamic Covalent Chemistry of Carbon Dioxide: Opportunities to Address Environmental Issues. Acc. Chem. Res. 50, 1692-1701 (2017).

24. M. Grzelczak, L. M. Liz-Marzán, R. Klajn, Stimuli-responsive self-assembly of nanoparticles. Chem. Soc. Rev. 48, 1342-1361 (2019).

25. J.-W. Lee, R. Klajn, Dual-responsive nanoparticles that aggregate under the simultaneous action of light and $\mathrm{CO}_{2}$. Chem. Commun. 51, 2036-2039 (2015).

26. H. Zhao et al., Reversible trapping and reaction acceleration within dynamically selfassembling nanoflasks. Nature Nanotechnol. 11, 82-88 (2016).

27. A. Dindi et al., Potential for the Simultaneous Capture and Utilization of $\mathrm{CO}_{2}$ Using Desalination Reject Brine: Amine Solvent Selection and Evaluation. Energy Procedia 63, 7947-7953 (2014).

28. H. P. Huang, Y. Shi, W. Li, S. G. Chang, Dual Alkali Approaches for the Capture and Separation of $\mathrm{CO}_{2}$. Energy \& Fuels 15, 263-268 (2001).

29. P. Zhu, H. Yang, C. Peng, X. Zhang, The Influence of Solvent and Temperature Upon the Aggregation of Poly(ethylene glycol). Macromol. Chem. Phys. 202, 1380-1383 (2001).

30. H. Shi et al., Phase Transition and Conformational Variation of N-Alkylated Branched Poly(ethyleneimine) Comblike Polymer. Macromolecules 37, 9933-9940 (2004).

31. W. Han et al., Water compatible supramolecular polymers: recent progress. Chem. Soc. Rev., (2021).

32. J. E. Greenleaf, A. K. SenGupta, Carbon Dioxide Regeneration of Ion Exchange Resins and Fibers: A Review. Solvent Extr. Ion Exch. 30, 350-371 (2012).

33. X. Wang et al., $\mathrm{CO}_{2}$ Absorption over Ion Exchange Resins: The Effect of Amine Functional Groups and Microporous Structures. Ind. Eng. Chem. Res. 59, 16507-16515 (2020).

34. T. Wang, T., K. S. Lackner, A. Wright, Moisture Swing Sorbent for Carbon Dioxide Capture from Ambient Air. Environ. Sci. Tech. 45, 6670-6675 (2011).

35. http:// www1.eere.energy.gov/manufacturing/industries_technologies/imf/pdfs/1797_advanced_ chlor-alkali.pdf 